\title{
Electrochemical Activation of Screen Printed Carbon Electrode for the Determination of Antibiotic Drug Metronidazole
}

\author{
Periyasamy Sundaresan ${ }^{1}$, Tse-Wei Chen ${ }^{1,2}$, Shen-Ming Chen ${ }^{1, *}$, Tien-Wen Tseng ${ }^{2}$, Xiaoheng Liu ${ }^{3, *}$ \\ ${ }^{1}$ Electroanalysis and Bioelectrochemistry Lab, Department of Chemical Engineering and \\ Biotechnology, National Taipei University of Technology, No.1, Section 3, Chung-Hsiao East Road, \\ Taipei 106, Taiwan, ROC. \\ 2 \\ Department of Chemical Engineering and Biotechnology, National Taipei University of Technology, \\ Taipei 106, Taiwan (ROC) \\ 3 Key Laboratory of Education Ministry for Soft Chemistry and Functional Materials, Nanjing University of \\ Science and Technology, Nanjing 210094, China. \\ *E-mail: smchen78@ms15.hinet.net (S.M.Chen); xhliu@ mail.njust.edu.cn (X.H. Liu)
}

doi: $10.20964 / 2018.02 .05$

Received: 16 October 2017 / Accepted: 22 November 2017 / Published: 28 December 2017

\begin{abstract}
Metronidazole (MTZ) is a potential drug for the treatment of antibiotic and antiprotozoal medications. However, the drug over dosage or contaminated water from the drug industry makes the human to fatal disease. Therefore, in this work we have concentrated the determination of metronidazole by the electrochemical technique. Thereby, we have utilized the activated screen printed carbon electrode (ASPCE) for the determination. This electrode was prepared by simple electrochemical cyclic voltammetry technique. Wherein, the SPCE was pre-anodized in the phosphate buffer solution and directly used for the determination. This electrode provides the better performance when compared with bare electrode. Moreover, it provides the selective and sensitive determination towards the MTZ with linear concentration ranges $0.05-563 \mu \mathrm{M} ; 753-2873 \mu \mathrm{M}$ and the lowest detection limit 0.01 $\mu \mathrm{M}$. The developed disposable sensor electrode is low cost and revealed high repeatability and reproducibility.
\end{abstract}

Keywords: Antibiotic drug, Metronidazole, Electrochemical detection, ASPCE

\section{FULL TEXT}

(C) 2018 The Authors. Published by ESG (www.electrochemsci.org). This article is an open access article distributed under the terms and conditions of the Creative Commons Attribution license (http://creativecommons.org/licenses/by/4.0/). 